\title{
Summary of FY-11 Krypton Capture Activities at the Idaho National Laboratory
}

Mitchell Greenhalgh

Troy G. Garn

Kristi Christensen

Veronica Rutledge

Jack D. Law

August 2011

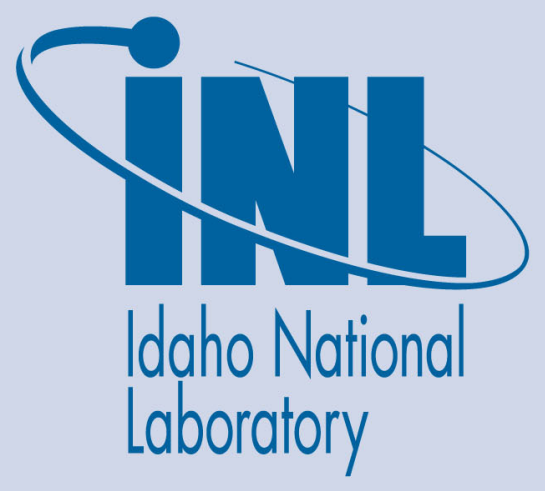

The INL is a U.S. Department of Energy National Laboratory operated by Battelle Energy Alliance 
INL/EXT-11-23139

FCRD-SWF-000312

\title{
Summary of FY-11 Krypton Capture Activities at the Idaho National Laboratory
}

\author{
Mitchell Greenhalgh \\ Troy G. Garn \\ Kristi Christensen \\ Veronica Rutledge \\ Jack D. Law
}

August 2011

\section{Idaho National Laboratory \\ Fuel Cycle Research \& Development Idaho Falls, Idaho 83415}

http://www.inl.gov

Prepared for the

U.S. Department of Energy

Office of Nuclear Energy

Under DOE Idaho Operations Office

Contract DE-AC07-05ID14517 


\section{DISCLAIMER}

This information was prepared as an account of work sponsored by an agency of the U.S. Government. Neither the U.S. Government nor any agency thereof, nor any of their employees, makes any warranty, expressed or implied, or assumes any legal liability or responsibility for the accuracy, completeness, or usefulness, of any information, apparatus, product, or process disclosed, or represents that its use would not infringe privately owned rights. References herein to any specific commercial product, process, or service by trade name, trade mark, manufacturer, or otherwise, does not necessarily constitute or imply its endorsement, recommendation, or favoring by the U.S. Government or any agency thereof. The views and opinions of authors expressed herein do not necessarily state or reflect those of the U.S. Government or any agency thereof. 


\section{CONTENTS}

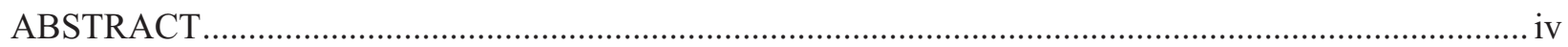

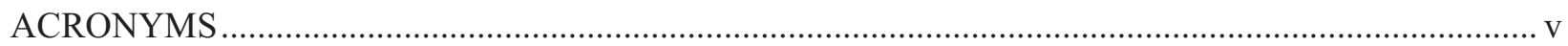

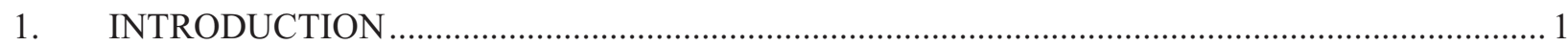

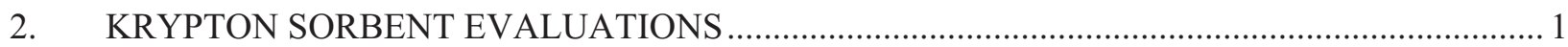

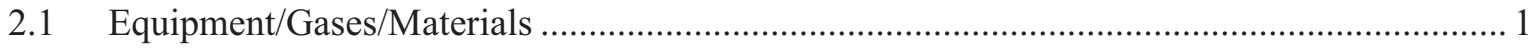

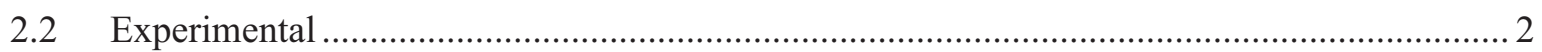

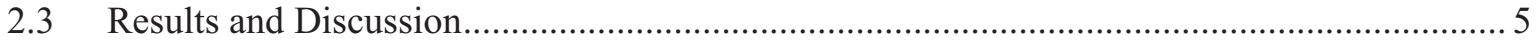

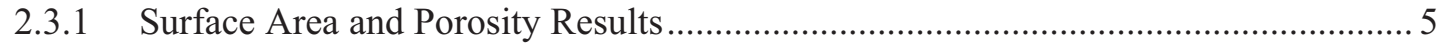

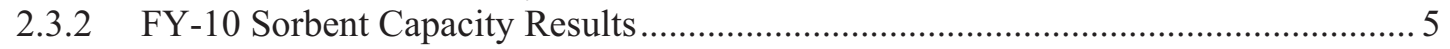

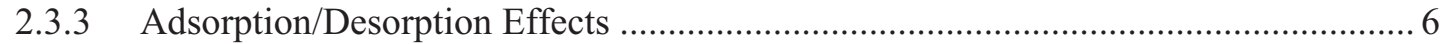

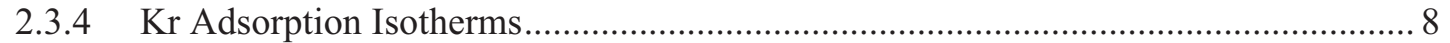

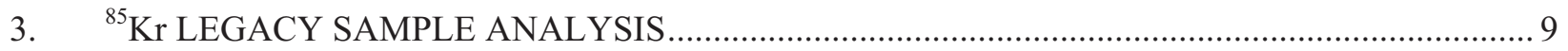

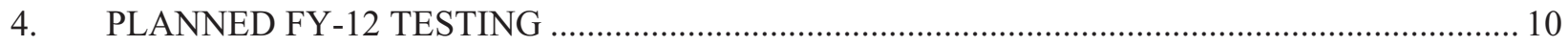

\section{FIGURES}

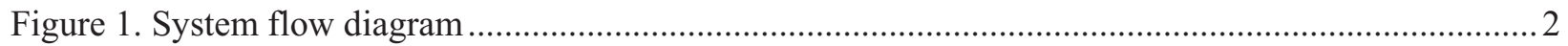

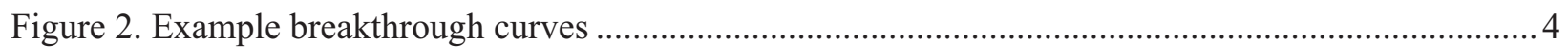

Figure 3. Baseline feed gas breakthrough curves................................................................................... 7

Figure 4. Photo of the sorbent removed from the cryostat after multiple cycles ........................................ 8

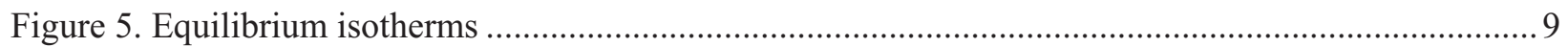

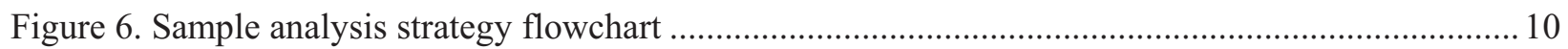

\section{TABLES}

Table 1. Summary of Kr adsorption test on FY-10 sorbent, sorbent mass 5.02g ................................... 3

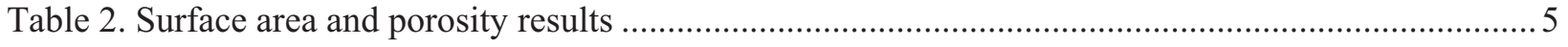

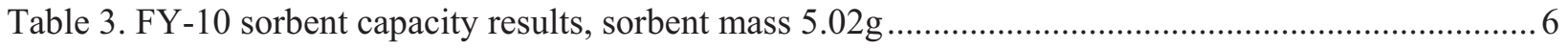

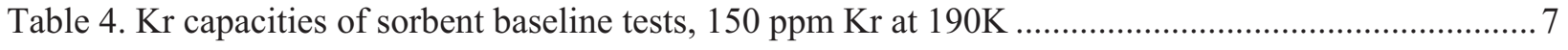

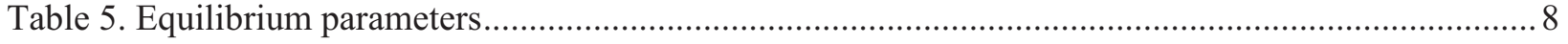




\begin{abstract}
Dissolution and voloxidation steps performed in the nuclear fuel reprocessing cycle result in the production of radioactive fission products in their respective off-gas streams. Various isotopes of $\mathrm{Kr}$ and $\mathrm{Xe}$ are included in the composition of the off-gas radioactive constituents. Depending on the fuel cooling times, $\mathrm{Kr}-85$, with a half-life of 10.7 years may need to be captured per EPA regulations for radioactive emissions. This report includes the results of the ongoing investigations into the solid phase adsorption of $\mathrm{Kr}$, specifically using thermal swing operation, as part of the Off-Gas Sigma Team effort. Experimental results produced from sorbent capacity evaluations have been included. Additionally, $\mathrm{Kr}$ adsorption isotherms were produced at two test temperatures to assist with modeling efforts. A final task was to define a strategy for legacy samples obtained from historical $\mathrm{Kr}$ immobilization experiments performed in the late '70's at the INL. The results reported herein will be included in a compiled final report describing the work completed by the Off-Gas Sigma team members in FY-11.
\end{abstract}




\section{ACRONYMS}

$\begin{array}{ll}\AA & \text { Angstroms } \\ \text { ANL } & \text { Argonne National Laboratory } \\ \text { BET } & \text { Brunauer, Emmet and Teller } \\ \text { DFT } & \text { Density Functional Theory } \\ \text { FY } & \text { Fiscal Year } \\ \text { GC } & \text { Gas Chromatograph } \\ \text { HIPed } & \text { Hot Isostatically Pressed } \\ \text { ICPP } & \text { Idaho Chemical Processing Plant } \\ \text { INL } & \text { Idaho National Laboratory } \\ \text { MFC } & \text { Mass Flow Controller } \\ \text { MOF } & \text { Metal Organic Framework } \\ \text { NDA } & \text { Non Destructive Analysis } \\ \text { NEAMS } & \text { Nuclear Energy Advanced Modeling and Simulation } \\ \text { ORNL } & \text { Oakridge National Laboratory } \\ \text { PI } & \text { Pressure Indicating } \\ \text { SafeSeps } & \text { Safeguards and Separations } \\ \text { sccm } & \text { Standard cubic centimeter per minute } \\ \text { SNL } & \text { Sandia National Laboratory } \\ \text { TCD } & \text { Thermal Conductivity Detector } \\ \text { UHP } & \text { Ultra High Purity }\end{array}$




\section{SEPARATIONS AND WASTE FORMS SUMMARY OF FY-11 KRYPTON CAPTURE ACTIVITIES AT THE IDAHO NATIONAL LABORATORY}

\section{INTRODUCTION}

This report summarizes the $\mathrm{Kr}$ capture activities completed in FY-11 at the INL. This work is a continuation of the previous activities from FY-09 and FY-10 in support of the Off-Gas Sigma Team objectives. The main goal of this activity is to evaluate selected solid sorbents for their feasible use for effective ${ }^{85} \mathrm{Kr}$ capture from used nuclear fuel reprocessing off-gas streams, most specifically fuel dissolution and voloxidation processing steps.

In FY-10, a custom built cryostat system was procured and installed at the INL to enable sorbents to be evaluated at temperatures from 150 to $500 \mathrm{~K}$ with sorbent bed sizes ranging from 2 to 600 grams. Sorbents were evaluated with various gases containing $\mathrm{Kr}, \mathrm{Xe}, \mathrm{N}_{2}$ and $\mathrm{He}$ at $190 \mathrm{~K}$. The initial sorbents evaluated were commercially available sorbents IONEX Ag-900 and Ag-mordenite "light phase" obtained from ORNL. A newly synthesized sorbent developed at the INL was also tested, herein referred to as FY-10 sorbent. Initial results were promising with the FY-10 sorbent, therefore most of the adsorption evaluations were performed with it.

Primarily using the FY-10 sorbent, evaluations were designed to elucidate the capacity for $\mathrm{Kr}$ in the presence of both $\mathrm{Xe}$ and $\mathrm{N}_{2}$. Four additional feed gases were acquired and utilized for the testing containing various compositions of $\mathrm{Kr}, \mathrm{Xe}$ and $\mathrm{N}_{2}$ with a He balance. The sorbent was activated under vacuum at $150^{\circ} \mathrm{C}$ for 18 hours to remove any residual water from the micropores prior to being placed in the cryostat. All evaluations were performed in the cryostat system where the column effluent was analyzed with a gas chromatograph (GC) for $\mathrm{Kr}$, Xe and $\mathrm{N}_{2}$ concentrations. $\mathrm{Kr}$ capacities were calculated from breakthrough curves generated from $\mathrm{GC}$ data. $\mathrm{Kr}$ adsorption isotherms on the FY-10 sorbent were also obtained to supply the NEAMS SafeSeps program with initial $\mathrm{Kr}$ adsorption data to support modeling development.

As a secondary project goal, a ${ }^{85} \mathrm{Kr}$ Legacy Sample Analysis Strategy was prepared to define a logical analysis plan for the legacy samples acquired in FY-10. These samples were prepared in the late 70's while testing $\mathrm{Kr}$ immobilization using zeolite $5 \mathrm{~A}$ material. The $\mathrm{Kr}$ was separated from the aluminum fuel dissolution process off-gas via the cryogenic distillation process at the Idaho Chemical Processing Plant (ICPP) at the INL. The separated Kr gas product was stored in pressurized cylinders and was used for the immobilization tests. Some of the $\mathrm{Kr}$ adsorbed 5A material was Hot Isostatically Pressed (HIPed) in a glass matrix. Small samples of loose zeolite material and HIPed zeolite material are now archived at the INL and have experienced more than three 10.7 year ${ }^{85} \mathrm{Kr}$ half-lives of decay. The analysis strategy was developed to ensure that the invaluable waste form information these samples could provide would be maximized while performing sequential analysis steps.

\section{KRYPTON SORBENT EVALUATIONS}

\subsection{Equipment/Gases/Materials}

The adsorption test equipment consists of the following; a feed gas mass flow controller (MFC) calibrated for a $0-100 \mathrm{sccm} /$ minute flow rate, the custom cryrostat column and a GC utilizing a Supelco carboxen 1010 plot fused silica capillary column with a thermal conductivity detector (TCD) to monitor the column effluent. A system flow diagram is shown in Figure 1. This equipment was employed for all adsorption evaluations performed in FY-11. 


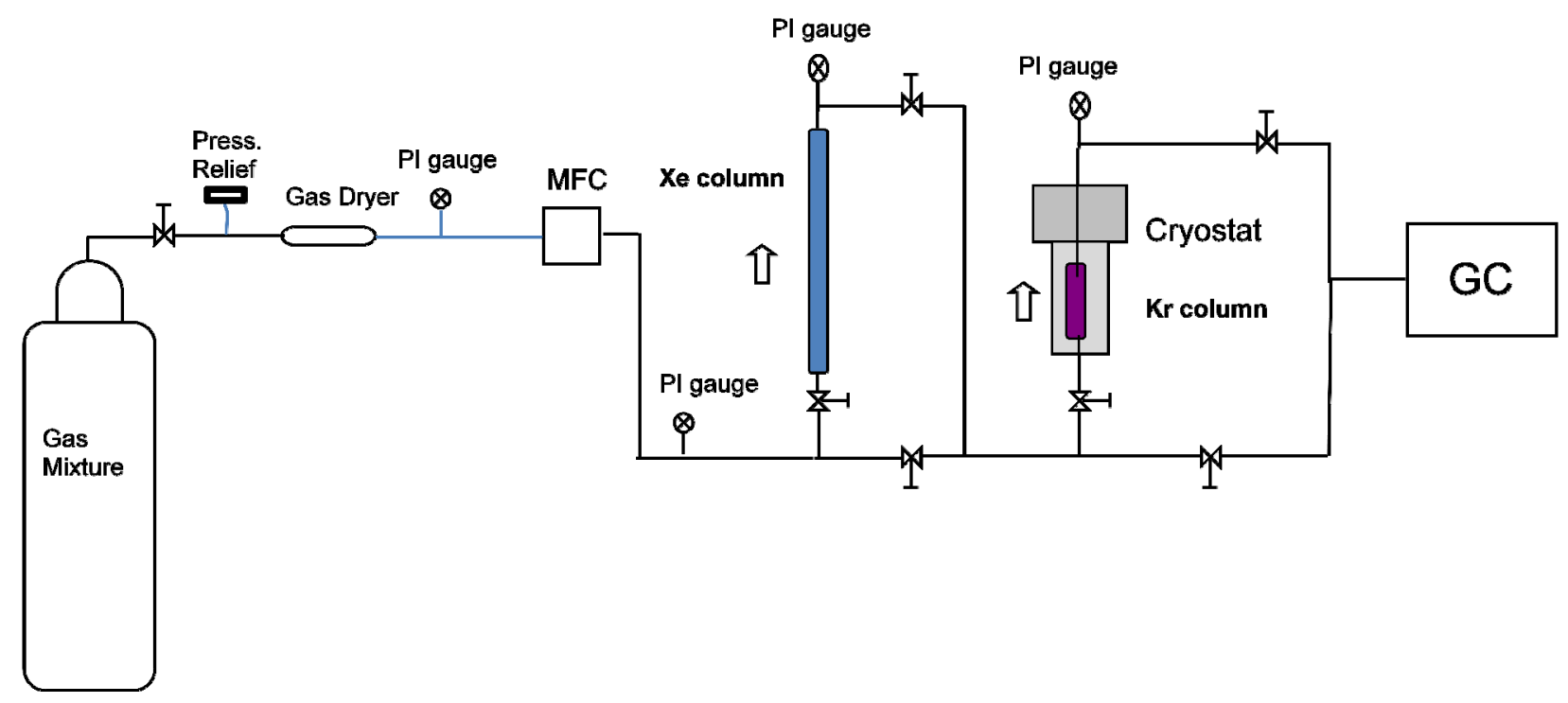

Figure 1. System flow diagram

To investigate the effects of competition/selectivity with $\mathrm{N}_{2}$ and $\mathrm{Xe}$ on $\mathrm{Kr}$ capacity, a total of seven different gas mixtures were available with varying compositions of $\mathrm{Kr}, \mathrm{Xe}, \mathrm{N}_{2}$ and $\mathrm{He}$, these gases were utilized for selectivity and isotherm testing. Concentrations of the respective individual components are $150 \mathrm{ppm} \mathrm{Kr}, 1000 \mathrm{ppm} \mathrm{Xe}$ and $79 \% \mathrm{~N}_{2}$ with the balance made up with He. These concentrations were chosen to represent fission product off-gas concentrations in a fuel reprocessing facility. Concentration calibrations for all test gases were performed using the GC prior to use.

Three sorbent materials were tested during the year. FY-10 sorbent and FY-11 sorbent, both synthesized at the INL, and NC-77 material developed at Sandia National Laboratory (SNL). Prior to testing, each material was analyzed for surface area and porosity using a Micrometrics ASAP 2020 surface area analyzer.

Initial adsorption tests were performed at ambient temperature to evaluate the efficacy for either $\mathrm{Kr}$ or $\mathrm{Xe}$ capture using test gases with or without $\mathrm{N}_{2}$. Ambient temperature tests with the NC-77 material indicated no measurable capacity for either $\mathrm{Kr}$ or $\mathrm{Xe}$, so its evaluation was discontinued. The FY-11 sorbent was synthesized mainly to evaluate Xe capacity, as such its use was primarily to act as a guard column for Xe removal. Minimal testing was completed at ambient temperature with the sorbent for evaluation as guard column material, however, more testing is warranted as initial tests were inconclusive. Initial ambient test results using the FY-10 sorbent indicated there was a measurable capacity for $\mathrm{Kr}$ and $\mathrm{Xe}$, thus the bulk of testing throughout the year focused on evaluating this sorbent. The following experimental section includes a description of the testing performed using the FY-10 sorbent.

\subsection{Experimental}

The FY-10 sorbent was prepared and sieved to a particle size range of 355-850 $\mu \mathrm{m}$. Analysis of the surface area and porosity was performed to confirm material preparation did not affect the porosity of the sorbent. The sorbent was activated by heating to $150^{\circ} \mathrm{C}$ for $18 \mathrm{hrs}$ under 20 inches of $\mathrm{Hg}$ vacuum. This activation was performed to ensure all of the residual water was removed from the micropores prior to use. A mass of 5.02 grams of the activated sorbent was placed into the cryostat cold column which was 
then installed in the cryostat apparatus. All tests performed during the year were performed on the same sorbent while the gas compositions and temperatures were varied. Periodically during the testing, the sorbent $\mathrm{Kr}$ capacity was measured using a "baseline" parameter test with $150 \mathrm{ppm} \mathrm{Kr}$ in $\mathrm{He}$ feed gas at $190 \mathrm{~K}$ to monitor the effects of adsorption/desorption thermal cycling on sorbent performance.

The experimental procedure was performed in the same manner for each test. The cryostat was cooled to the desired temperature with Ultra High Purity (UHP) He flow at $\sim 70 \mathrm{sccm} / \mathrm{min}$. Once the system had reached the selected temperature set point, the He was turned off and the desired feed gas was introduced into the cryostat column with a cross-sectional area of $0.713 \mathrm{~cm}^{2}$ at flowrates ranging from $50-72$ $\mathrm{sccm} / \mathrm{min}$. The column effluent was monitored with the GC until a minimum of $\sim 90 \%$ breakthrough was attained as indicated by GC peak areas. This would complete the adsorption phase of the experiment. At breakthrough, the feed gas was stopped, the He flow was started and the cryostat was heated to $316 \mathrm{~K}$ for desorption. This phase was continued until there was no detectable $\mathrm{Kr}, \mathrm{N}_{2}$ or Xe on the GC chromatogram. The detection limit of the GC for $\mathrm{Kr}, \mathrm{Xe}$ and $\mathrm{N}_{2}$ was $\sim 10 \mathrm{ppm}$. The experiments were designed for two different purposes; the first was to evaluate the impacts of $\mathrm{Xe}$ and $\mathrm{N}_{2}$ on the $\mathrm{Kr}$ capacity at $190 \mathrm{~K}$, and the second was to obtain the necessary data to create $\mathrm{Kr}$ adsorption isotherms at 190 and $222 \mathrm{~K}$. The isotherm data was supplied to NEAMS SafeSeps program in support of their modeling efforts. Table 1 summarizes the variety of tests performed throughout the year

To determine the correct capacity of each sorbent by accounting for gas dilution by volume, tests were performed at room temperature with selected gases. The time required for the gas concentration at the effluent of the cryostat to match the calibrated concentration of the feed gas was measured. This information was used to determine correction factors to account for the effects of dilution in the system. These correction factors were included in the final $\mathrm{Kr} / \mathrm{Xe}$ capacities reported in Tables 3 and 4.

Table 1. Summary of Kr adsorption test on FY-10 sorbent, sorbent mass $5.02 \mathrm{~g}$

Adsorption

Temperature Feed Gas Composition

(K)

190

$150 \mathrm{ppm} \mathrm{Kr}$ in $\mathrm{He}$

190

190

150 ppm $\mathrm{Kr} 79 \%$ N2 in $\mathrm{He}$

190

150 ppm Kr, 1020 ppm Xe in $\mathrm{He}$

190

150 ppm Kr, 999 ppm Xe, 79.1\% N2 in He

190

$84.5 \mathrm{ppm} \mathrm{Kr}$ in $\mathrm{He}$

190

$111 \mathrm{ppm} \mathrm{Kr}$ in $\mathrm{He}$

190

333 ppm $\mathrm{Kr}$ in $\mathrm{He}$

190

$889 \mathrm{ppm} \mathrm{Kr}$ in $\mathrm{He}$

190

1675 ppm $\mathrm{Kr}$ in $\mathrm{He}$

222

2544 ppm $\mathrm{Kr}$ in $\mathrm{He}$

222

$150 \mathrm{ppm} \mathrm{Kr}$ in $\mathrm{He}$

222

$861 \mathrm{ppm} \mathrm{Kr}$ in $\mathrm{He}$

222

1707 ppm $\mathrm{Kr}$ in $\mathrm{He}$

2544 ppm $\mathrm{Kr}$ in $\mathrm{He}$ 
Breakthrough curves are generated by plotting the concentration of the constituent of interest (C) in the column effluent as a function of the volume $(v)$ of gas processed. The collected breakthrough curves are used to calculate the sorbent capacity (SC) for each constituent in the feed gas. The sorbent capacities are calculated from the following equation:

$$
S C=\int_{0}^{V} \frac{\left(C_{0}-C\right)}{M} d v
$$

Where:

$$
\begin{aligned}
& \mathrm{V}=\text { total volume processed at breakthrough, liters } \\
& \mathrm{C}_{0}=\text { concentration in feed, } \mathrm{mol} / \mathrm{L} \\
& \mathrm{C}=\text { concentration in effluent at } v, \mathrm{~mol} / \mathrm{L} \\
& \mathrm{M}=\text { sorbent mass, grams }
\end{aligned}
$$

Because $\mathrm{C}_{\mathrm{o}}$ and $\mathrm{M}$ are constant, Equation 1 can be rewritten as:

$$
S C=\frac{1}{M}\left(\mathrm{CoV}-\int_{0}^{V} C d v\right)
$$

The statistical software TableCurve ${ }^{\circ}$, from Jandel Scientific, was used to find the best-fit for equations representing the breakthrough curves. The software was used to define the area below the breakthrough curve to obtain the value for the last term in Equation 2. This result was then subtracted from the total area $\mathrm{C}_{\mathrm{o}} \mathrm{V}$ to give the amount of $\mathrm{Kr}$ and $\mathrm{Xe}$ adsorbed on the material. The adsorbed amount was then divided by the sorbent bed mass to give a final sorbent capacity in mol $\mathrm{Kr}$ or $\mathrm{Xe} /$ grams sorbent. An example breakthrough curve using GC generated data for $\mathrm{Kr}$, Xe and $\mathrm{N}_{2}$ can be seen in Figure 2. From this curve it is apparent that the nitrogen breaks through first followed by the $\mathrm{Kr}$ and finally $\mathrm{Xe}$ for the sorbent tested. The results of the fiscal year's testing are presented in the following section.

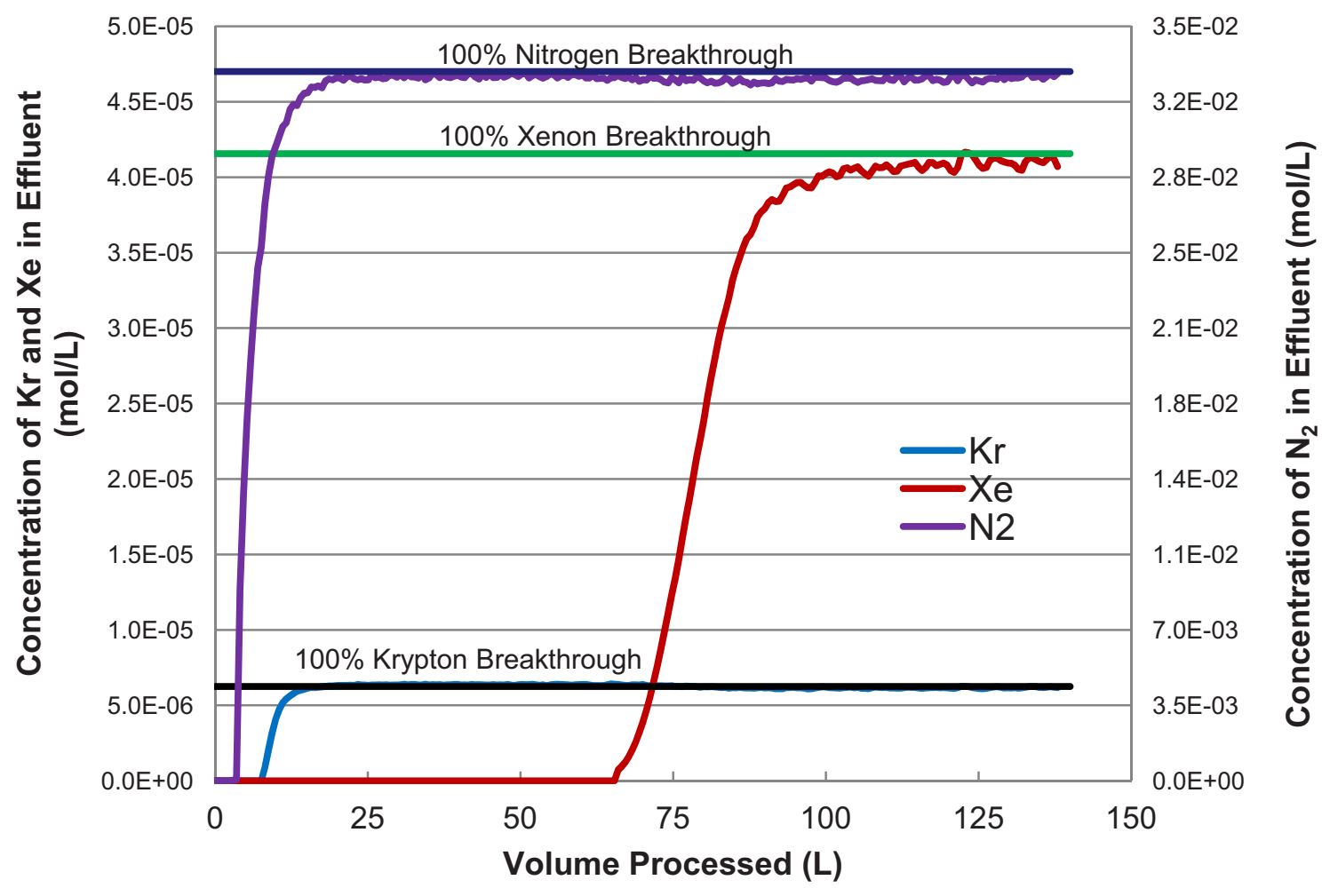

Figure 2. Example breakthrough curves 


\subsection{Results and Discussion}

\subsubsection{Surface Area and Porosity Results}

Measurements of the surface area and microporosity were performed on all of the available sorbents with a Micromeritics ASAP 2020 utilizing $\mathrm{N}_{2}$ adsorption. Using Brunauer, Emmet, and Teller (BET) and Langmuir theories, surface areas were calculated while micropore area and volume in the range of 4-10 angstroms $(\AA)$ were determined from the Density Functional Theory (DFT). The 4-10 $\AA$ range is reported because the relative diameters of $\mathrm{Kr}, \mathrm{Xe}$ and $\mathrm{N}_{2}$ are within this range. The results indicate both Agmordenite sorbents have lower surface area, micropore surface area and micropore volumes than the INL sorbents. The reduced surface area and micropore volumes are likely due to the pelletization process used for Ag-mordenite production. Although the NC-77 has a high surface area, its micropore area and volume are quite low in the $4-10 \AA$ range. The results of the surface area and porosity analyses are located in Table 2 for all of the sorbents.

Table 2. Surface area and porosity results

\begin{tabular}{|c|c|c|c|c|}
\hline Sorbent & $\begin{array}{c}\text { BET surface area } \\
\left(\mathrm{m}^{2} / \mathrm{g}\right)\end{array}$ & $\begin{array}{l}\text { Langmuir surface } \\
\text { area }\left(\mathrm{m}^{2} / \mathrm{g}\right)\end{array}$ & $\begin{array}{c}\text { DFT } \\
\text { micropore area } \\
\left(\mathrm{m}^{2} / \mathrm{g}\right)\end{array}$ & $\begin{array}{c}\text { DFT } \\
\text { micropore } \\
\text { volume }\left(\mathrm{cm}^{3} / \mathrm{g}\right)\end{array}$ \\
\hline IONEX Ag900 & 14 & $\mathrm{~N} / \mathrm{A}$ & 2.4 & 0.001 \\
\hline Ag-mord-LP & 59 & N/A & 40 & 0.01 \\
\hline $\mathrm{NC}-77$ & 298 & 398 & 39 & 0.01 \\
\hline FY-10 & 336 & 440 & 427 & 0.1 \\
\hline FY-11 & 80 & 104 & 128 & 0.03 \\
\hline
\end{tabular}

\subsubsection{FY-10 Sorbent Capacity Results}

To test the effects of Xe and $\mathrm{N}_{2}$ on $\mathrm{Kr}$ adsorption, the FY-10 sorbent was evaluated with four feed gases at 190K. The reported $\mathrm{Kr}$ (and Xe if present) sorbent capacities were calculated using breakthrough curves generated from the GC data using the previously described technique. The MFC utilized for these tests was factory calibrated for a $79 \% \mathrm{~N}_{2}$ and $21 \% \mathrm{He}$ mixture. It was set to $50 \mathrm{sccm} / \mathrm{min}$ for each test. For gases without $\mathrm{N}_{2}$, the flowrate was calculated using the appropriate gas correction factors supplied by the manufacturer. This adjustment resulted in an actual flowrate of $69 \mathrm{sccm} / \mathrm{min}$ for these gases. This change in actual flow results in a larger total volume being processed and hence, a slight increase in the capacities in comparison to those previously reported. The results are reported in Table 3 and indicate as expected that both $\mathrm{Xe}$ and $\mathrm{N}_{2}$ affect the $\mathrm{Kr}$ capacity. The sorbent demonstrated a reasonable capacity for $\mathrm{Kr}$ in the absence of $\mathrm{N}_{2}$ and $\mathrm{Xe}$, however, the presence of $\mathrm{N}_{2}$ decreased the $\mathrm{Kr}$ capacity by nearly three orders of magnitude while Xe lowered it by only one order of magnitude. This suggests that the $\mathrm{Kr}$ capacity of the sorbent is impacted more by the presence of high concentration $\mathrm{N}_{2}$ than by Xe. It is interesting to note that in the presence of both $\mathrm{Xe}$ and $\mathrm{N}_{2}$, the $\mathrm{Kr}$ capacity was reduced by only two orders of magnitude. More evaluations are needed to better understand this phenomenon and to investigate the potential of removing the $\mathrm{N}_{2}$ from the gas stream to increase $\mathrm{Kr}$ capture. The FY-10 sorbent $\mathrm{Kr}$ capacities reported below for a $\mathrm{Kr} / \mathrm{He}$ gas mixture are speculatively higher than those reported in previous literature. The speculation arises from not enough information being included in previous literature as to the actual 
physical characteristics of the sorbent tested i.e. powder form, engineered form, etc. The FY-10 sorbent is in an engineered form desirable for use in actual process applications.

Table 3. FY-10 sorbent capacity results, sorbent mass $\mathbf{5 . 0 2 \mathrm { g }}$

\begin{tabular}{ccc}
\hline Feed gas mixture & $\begin{array}{c}\text { Kr Capacity } \\
(\mathbf{m o l} / \mathbf{g})\end{array}$ & $\begin{array}{c}\text { Xe Capacity } \\
(\mathbf{m o l} / \mathbf{g})\end{array}$ \\
\hline \hline $\mathrm{Kr} / \mathrm{He}$ & $1.04 \mathrm{e}-4$ & $\mathrm{~N} / \mathrm{A}$ \\
$\mathrm{Kr} / \mathrm{N}_{2} / \mathrm{He}$ & $5.83 \mathrm{e}-7$ & $\mathrm{~N} / \mathrm{A}$ \\
$\mathrm{Kr} / \mathrm{Xe} / \mathrm{He}$ & $1.13 \mathrm{e}-5$ & $1.10 \mathrm{e}-3$ \\
$\mathrm{Kr} / \mathrm{Xe} / \mathrm{N}_{2} / \mathrm{He}$ & $7.67 \mathrm{e}-6$ & $6.36 \mathrm{e}-4$ \\
\hline
\end{tabular}

\subsubsection{Adsorption/Desorption Effects}

The same 5.02 gram mass of FY-10 sorbent was utilized for all evaluations during the year. Intermittently, baseline tests using the $\mathrm{Kr} / \mathrm{He}$ feed gas, at $150 \mathrm{ppm} \mathrm{Kr}$ and $190 \mathrm{~K}$, were performed on the sorbent. These tests were intended to ensure that the adsorption/desorption thermal cycles were not impacting the sorbent capacities. If the $\mathrm{Kr}$ breakthrough curve and calculated capacity remains relatively unchanged after undergoing multiple thermal cycles, the sorbent's thermal stability and cycling assets are validated. Figure 3 is a compilation of the "baseline" breakthrough curves from these tests. It can be seen from the graph that the sorbent's breakthrough curve remained the same over the course of the testing. Table 4 lists the calculated capacities of $\mathrm{Kr}$ for each test and indicates that they are in excellent agreement with each other. 


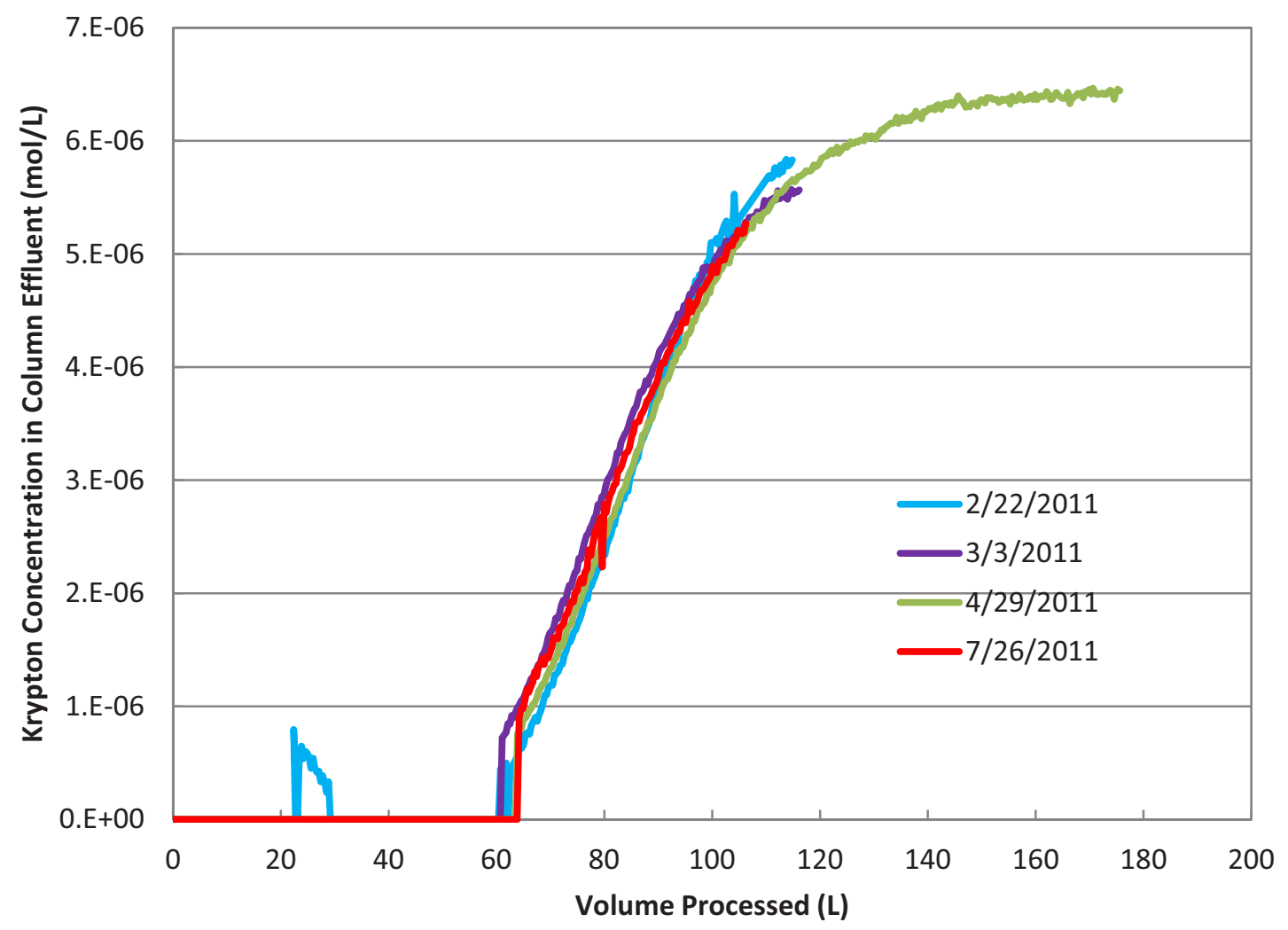

Figure 3. Baseline feed gas breakthrough curves

Table 4. Kr capacities of sorbent baseline tests, $150 \mathrm{ppm} \mathrm{Kr}$ at $190 \mathrm{~K}$

\begin{tabular}{ccc}
\hline Test Date & $\begin{array}{c}\text { Kr capacity } \\
\text { (moles/g sorbent) }\end{array}$ & Breakthrough (\%) \\
\hline \hline $02 / 22 / 2011$ & $1.02 \mathrm{e}-4$ & 93.8 \\
$03 / 03 / 2011$ & $1.00 \mathrm{e}-4$ & 89.5 \\
$04 / 29 / 2011$ & $1.12 \mathrm{e}-4$ & 100 \\
$07 / 26 / 2011$ & $1.00 \mathrm{e}-4$ & 84.7 \\
\hline
\end{tabular}

At the conclusion of all the testing, the FY-10 sorbent was removed from the cryostat cold column. The sorbent visually appeared to be in the same condition as when it was first placed in the system. A mass measurement indicated all 5.02 grams were recovered. The relatively unchanged physical structure together with no mass lost reveals that the sorbent held up well to the thermal cycling and is quite robust for operating conditions tested. A final surface area and porosity analysis was completed on this cycled sorbent with results indicating negligible change when compared with the initial analysis. Figure 4 is a picture of the sorbent upon removal from the cryostat. The slight yellowish discoloration was noted prior to use, resulting from the initial activation sequence. 


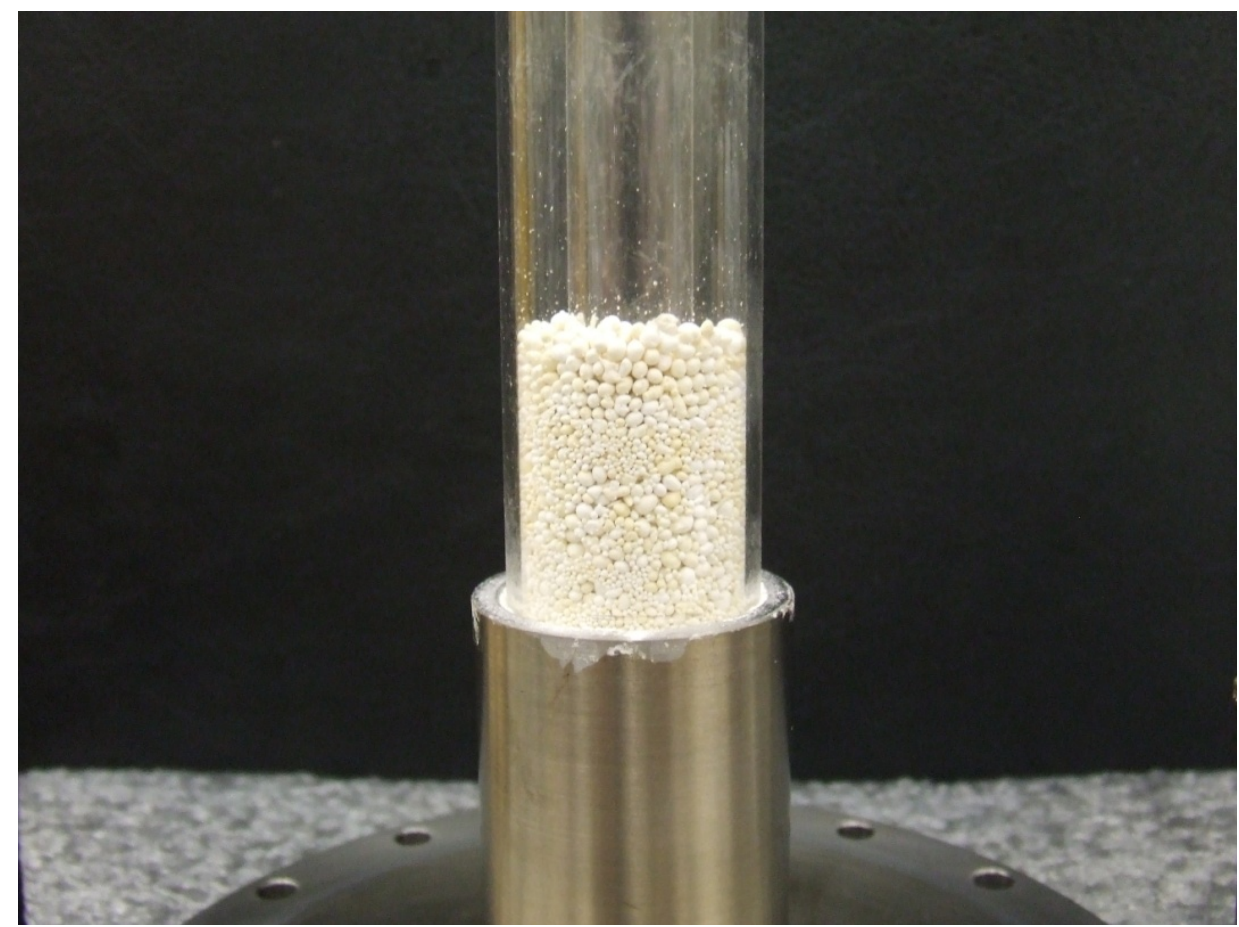

Figure 4. Photo of the sorbent removed from the cryostat after multiple cycles

\subsubsection{Kr Adsorption Isotherms}

In support of the NEAMS SafeSeps modeling effort, two $\mathrm{Kr}$ adsorption isotherms were generated. Isotherm data was collected at temperatures of $190 \mathrm{~K}$ and $220 \mathrm{~K}$, with feed concentrations ranging from 75 ppm to $2544 \mathrm{ppm} \mathrm{Kr}$ in helium. Kr feed concentration was varied by adding a second MFC to the system shown in Figure 1, and diluting the $2544 \mathrm{ppm} \mathrm{Kr}$ feed gas using helium to the desired concentration.

The purpose of the isotherms is to provide experimentally measured values for equilibrium parameters to be used as input data for modeling. It was determined that the Langmuir equilibrium isotherm was the best fit for the data set. The Langmuir equilibrium model is written as:

$$
q=\frac{q_{\max } K_{e q} C}{1+K_{e q} C}
$$

Where $\mathrm{q}$ is the sorbent capacity at equilibrium with feed concentration $(\mathrm{C}), \mathrm{q}_{\max }$ is maximum capacity of the sorbent at the specified temperature, and $\mathrm{K}_{\mathrm{eq}}$ is the equilibrium constant. The values for $\mathrm{q}_{\max }$ and $\mathrm{K}_{\mathrm{eq}}$ at $190 \mathrm{~K}$ and $220 \mathrm{~K}$ are reported in Table 5 . The isotherm data and corresponding Langmuir fits are shown in Figure 5.

Table 5. Equilibrium parameters

\begin{tabular}{ccc}
\hline Temperature & $\mathrm{q}_{\max }(\mathrm{mol} / \mathrm{kg})$ & $\mathrm{K}_{\mathrm{eq}}\left(\mathrm{m}^{3} / \mathrm{mol}\right)$ \\
\hline \hline $191 \mathrm{~K}$ & 0.94 & 23.4 \\
$220 \mathrm{~K}$ & 0.20 & 8.4 \\
\hline
\end{tabular}




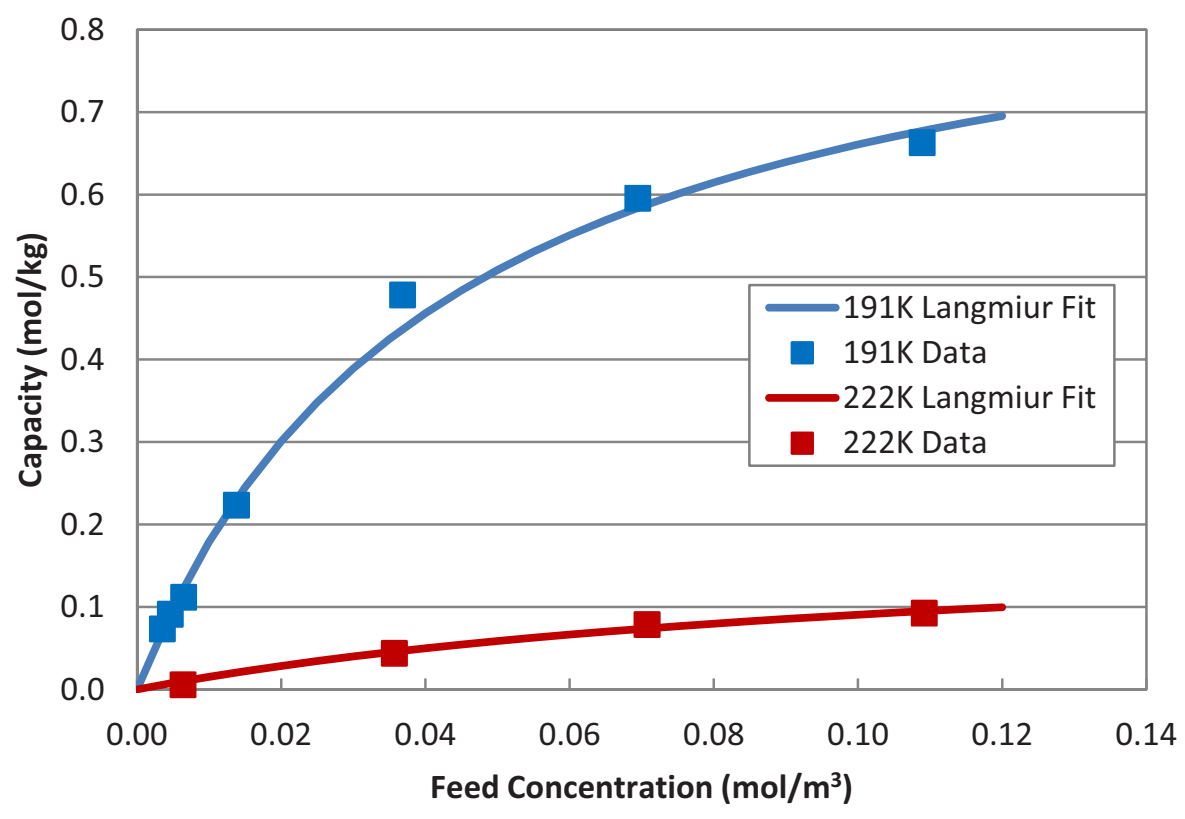

Figure 5. Equilibrium isotherms

\section{3. ${ }^{85} \mathrm{Kr}$ LEGACY SAMPLE ANALYSIS}

A ${ }^{85} \mathrm{Kr}$ Legacy Sample Analyses Strategy was prepared during the FY-11 activities. This plan is intended to ensure a logical analysis sequence is followed so that the invaluable waste form information will not be jeopardized over the course of the performed analyses. The general sequence of the work will be in three stages as shown in Figure 6. Stage one will include non destruction analysis (NDA) characterization of the samples (radiation levels, contamination levels and gamma signature) and neutron imaging. The initial characterization and imaging will support the selection of the handling facilities for unpackaging/disassembly and sub-sampling, the development of a disassembly plan, the development of shipping plans and the initial identification of facilities for sample analysis. Stage two is the unpackaging/gas sampling/disassembly/sub-sampling and packaging for shipment to the analysis sites. The final stage is the analysis of the subsamples at the appropriate laboratories. Analyses of these legacy samples is expected to give valuable information as to the state of the samples, corrosion of the containers and the potential radiation damage to the crystal structure of the zeolite material. 


\section{Evaluation Steps}

Planning

Stage One

Stage Two

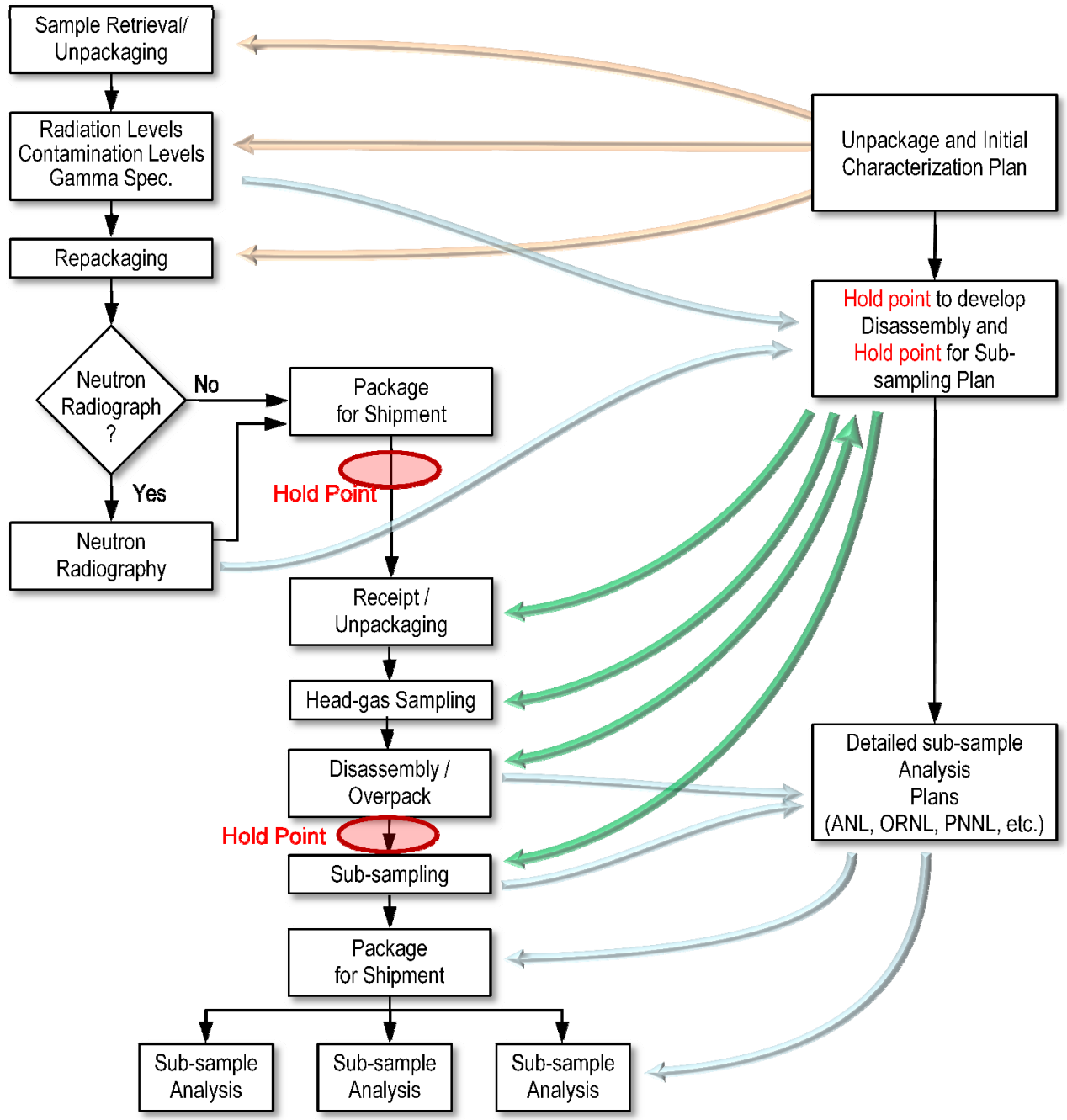

Figure 6. Sample analysis strategy flowchart

\section{PLANNED FY-12 TESTING}

The research will continue to investigate FY-10 sorbent utilizing thermal and potentially pressure swing operations, evaluate $\mathrm{O}_{2}$ impacts to capacities, and collect necessary data for adsorption isotherm development. Ultimately, the data can be used to perform equipment scale-up calculations supporting process feasibility determinations.

More FY-11 sorbent will need to be prepared so evaluations at ambient temperatures can be completed to investigate its use as a Xe guard column. FY-11 sorbent may also be tested at reduced temperatures to compare $\mathrm{Kr} / \mathrm{Xe}$ capacities with FY-10 sorbent.

MOFs and other sorbents will be evaluated in the cryostat as they become available and new sorbents such as titanosilicates or inorganic nano-materials may be investigated as time permits.

Stage one of the legacy sample analysis strategy will be undertaken. Results of the completion for stage one will be used to implement stage two of the strategy. 